\title{
PENERAPAN KESELARASAN RANGKAIAN ALUR (NARASI) DAN PENGALAMAN RUANG DALAM PSIKOLOGI ARSITEKTUR
}

\author{
Rafi Mentari ${ }^{1}$, Sarah Aisha ${ }^{2}$, Marselly Dwiputri ${ }^{3}$ \\ ${ }^{1}$ Universitas Indraprasta PGRI, Program Studi Arsitektur \\ rafimentari@gmail.com \\ ${ }^{2}$ Universitas Indraprasta PGRI, Program Studi Arsitektur \\ sarachaisha@gmail.com \\ ${ }^{3}$ Universitas Indraprasta PGRI, Program Studi Arsitektur \\ marselly_dwiputri@yahoo.com
}

\begin{abstract}
In this increasingly advanced era, there are more and more developments in architectural spaces that provide a variety of experiences for the users. These architectural spaces are generally created from the elements in the form of the surface (floor), the wall (barrier), and the roof (ceiling) which are combined with accessibility for user movement. The purpose of these elements is to fulfill space requirements that can provide a specific experience for the user. These developments are further explored in the article, in term of psychological and its relation to architecture, that the alignment of a series of plot (narrative) and spatial experiences can evoke positive emotions and feelings. This article aims to analyze the processing of a series of plot (narrative) in space so that later alignment can provide a different experience individually by emphasizing the supporting elements.
\end{abstract}

Key Words: plot, experience, user, space, psychology architecture

\begin{abstract}
Abstrak : Di era yang semakin maju ini, semakin banyak perkembangan ruang-ruang arsitektural yang memberikan ragam pengalaman bagi pengguna (user) yang berada didalamnya. Ruang-ruang arsitektural tersebut secara umum terbentuk dari pengolahan elemen-elemen berupa bidang alas (lantai), bidang dinding (pembatas), dan bidang atap (langit-langit) yang dikombinasikan dengan rangkaian alur bagi pergerakan pengguna dalam ruang. Pengolahan elemen-elemen tersebut sebagai pemenuhan kebutuhan ruang yang mampu memberikan pengalaman tertentu bagi pengguna. Perkembangan-perkembangan ini kemudian ditelusuri lebih lanjut dalam artikel, secara psikologi dan kaitannya dengan arsitektur, keselarasan rangkaian alur (narasi) dan pengalaman ruang dapat membangkitkan emosi dan perasaan yang bersifat positif. Artikel ini bertujuan untuk menganalisis pengolahan rangkaian alur (narasi) pada ruang sehingga nantinya tercipta keselarasan yang dapat memberikan pengalaman berbeda secara individu dengan penekanan pada elemen pendukung.
\end{abstract}

Kata Kunci : alur, pengalaman, pengguna, ruang, psikologi arsitektur

\section{PENDAHULUAN}

Arsitektur dapat dilihat sebagai salah satu pembentuk ruang dimana secara jelas (baik secara fisikal maupun sosial) dapat memberikan pengalaman bagi penggunanya Berkembangnya bentuk dan jenis ruang sebagai wadah bagi manusia sebagai suatu eksplorasi yang memberikan beragam pengalaman tertentu, secara psikologi dan kaitannya dengan arsitektur, yang bersifat positif. Fenomena ini menjadi menarik untuk ditelusuri dan dianalisis lebih lanjut terkait pengolahan rangkaian alur (akses dan pergerakan) pada ruang sehingga nantinya tercipta keselarasan yang dapat memberikan pengalaman meruang secara naratif, sehingga dapat memprediksi outcome yang dapat terjadi (potensi) dan kemungkinan intervensi arsitektural (oportunitas) menjadi suatu gagasan ide yang berkaitan dengan psikologi arsitektur.
Psikologi arsitektur adalah sebuah bidang studi yang mempelajari hubungan antara lingkungan binaan dan pengaruhnya terhadap perilaku manusia yang ada di dalamnya. Merupakan sebuah kajian khusus yang berorientasi pada kondisi psikologis sekelompok pengguna bangunan dengan karakteristik sejenis (Halim, 2005). Oleh karena itu, suatu ruang arsitektural tidak dilihat hanya sebagai wadah bernaung, melainkan sebuah tempat yang memberi respon positif bagi penggunanya.

Menganalisis fenomena yang terjadi disekitar, maka akan mengimplikasi keterkaitan yang memberikan beragam potensi dan oportunitas, seperti pada minat dan aktivitas akan memunculkan kemungkinan terhadap struktur sosial, atau pada elemen dan fungsi akan memunculkan kemungkinan organisasi penataan (Schmidt \& Wagner, 2001) dan juga untuk 
menyerap informasi yang didapat agar dapat diproses secara efisien (Raffestin, 1980). Dengan menggambarkan secara visual tentang garis besar suatu konteks dimana manusia berinteraksi, serta dimana tindakan menciptakan reaksi, akan meningkatkan pemahaman tentang hubungan antara keadaan (aktivitas dan keseharian) yang terjadi di dalam konteks dan manusia yang terlibat (Patchett \&Wilhelm, 1995). Pengalaman meruang akan menggali oportunitas atau mengembangkan potensi berupa ruang interaksi hubungan sosial. Dipengaruhi oleh kemudahan akses bagi pengguna yang terlibat dan orientasi terhadap berapa banyak orang yang dapat terhubung kedalam ruang lingkup tersebut (Yatmo et al., 2013).

Dari hal-hal diatas, artikel ditulis sebagai penelitian untuk memahami pembentukan keselarasan antara rangkaian alur untuk memberikan pengalaman yang berbeda, serta berkesan, bagi pengguna ruang. Bukan hanya sekedar menggunakan ruang, tetapi lebih kepada pengalaman ruang secara emosional dalam lingkup psikologi arsitektur.

\section{METODOLOGI}

Metode yang digunakan adalah Metode Kualitatif (Qualitative Method), yaitu metode pengumpulan data, analisis, dan penulisan laporan (Creswell, 2002). Metode ini kemudian disandingkan dengan pendekatan berbasis narasi. Mengutip Patridge (1977) narasi disini memiliki pengertian "to tell the particulars of an event or an act" yang diartikan untuk memberi tahu hal-hal khusus dari suatu peristiwa atau tindakan. Pendekatan ini diperkuat oleh pernyataan De Certeau (1984), dimana dijelaskan bahwa narasi didalam arsitektur itu sendiri, terbentuk dalam dimensi ruang dan waktu, yang mana proses melihatnya berdasarkan pengalaman..

\section{HASIL DAN PEMBAHASAN}

Penerapan keselarasan antara rangkaian alur dan pengalaman terhadap ruang dalam psikologi arsitektur mengambil studi analisis galeri seni. Berdasarkan Oxford Dictionary, secara umum, gallery memiliki definisi "a room or building for the display or sale of works of art" sedangkan art merupakan "the expression or application of human creative skill and imagination, typically in a visual form such as painting or sculpture, producing works to be appreciated primarily for their beauty or emotional power".

Sehingga, dapat diartikan bahwa galeri seni merupakan sebuah ruangan atau gedung, dimana berbagai bentuk karya seni ditampilkan kepada publik dan dapat juga diperjual belikan. Dalam galeri seni, bagian yang paling penting atau yang paling ditonjolkan adalah ruang pamerannya. Dalam proses mendesain, ruang pameran perlu mendapatkan perhatian khusus, karena ruang pameran merupakan ruang inti dari sebuah galeri seni yang berfungsi untuk memamerkan karyakarya seni.

Francis D.K. Ching (2012) menuliskan bahwa ruang terbentuk dari adanya hubungan majemuk antara ruang dan unsur-unsur lain yang mendukung, seperti; bidang alas (lantai), bidang dinding (pembatas), dan bidang atap (langitlangit). Hal-hal tersebut kemudian diolah sebagai pemenuhan kebutuhan ruang yang mampu membangkitkan emosi. Disini penelitian memfokuskan pengolahan rangkaian alur pada ruang, sehingga tercipta keselarasan yang dapat memberikan pengalaman berbeda secara tersendiri bagi pengunjung galeri seni dengan memberikan penekanan pada unsur-unsur pendukungnya.
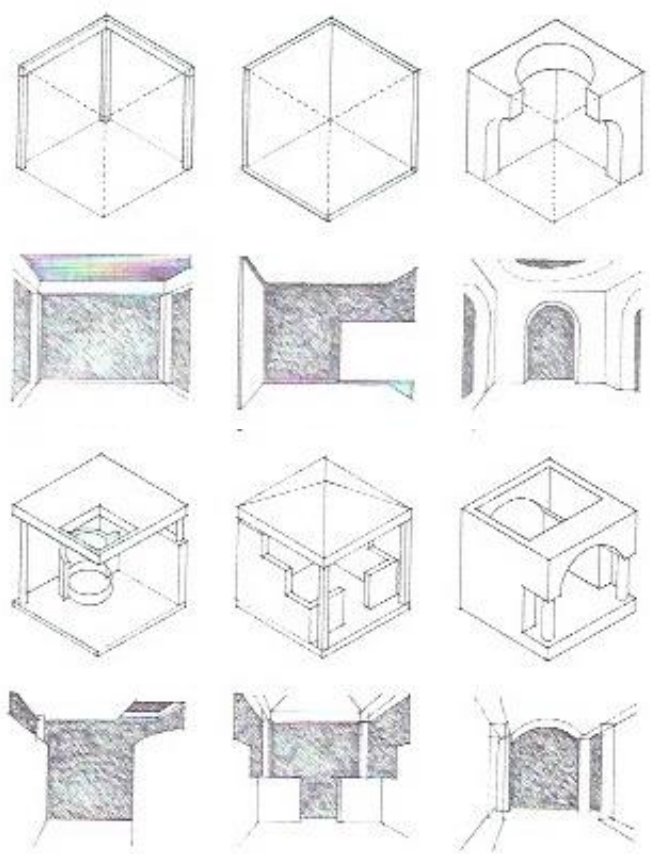

Gambar 1 Hubungan majemuk antara ruang dan unsurunsur lain yang mendukung (Ching, 2012)

Berangkat dari hal-hal diatas, dilakukan eksplorasi terhadap proses pencarian tipologi untuk kebutuhan pengetahuan dalam penerapan keselarasan antara rangkaian alur dalam ruangruang pameran di galeri seni untuk memberikan pengalaman yang berbeda. Pencarian tipologi yang dilakukan bertujuan untuk memahami dan mempelajari konteks yang ada, terkait dengan ruang-ruang standar yang dibutuhkan untuk galeri seni (Colquhoun, 1996). 
Hasil pencarian tipologi tersebut sebagai pemahaman makna dari tipe-tipe suatu arsitektur tertentu, dimana posisi dan tujuan dalam mempelajari tipe-tipe yang ada hanya untuk sekedar memahami kekhasan yang ada pada tipologi galeri seni, yang nantinya akan dikembangkan untuk menjadikannya sebagai sesuatu yang memberikan rasa ruang dan pengalaman beragam bagi pengunjung galeri seni.

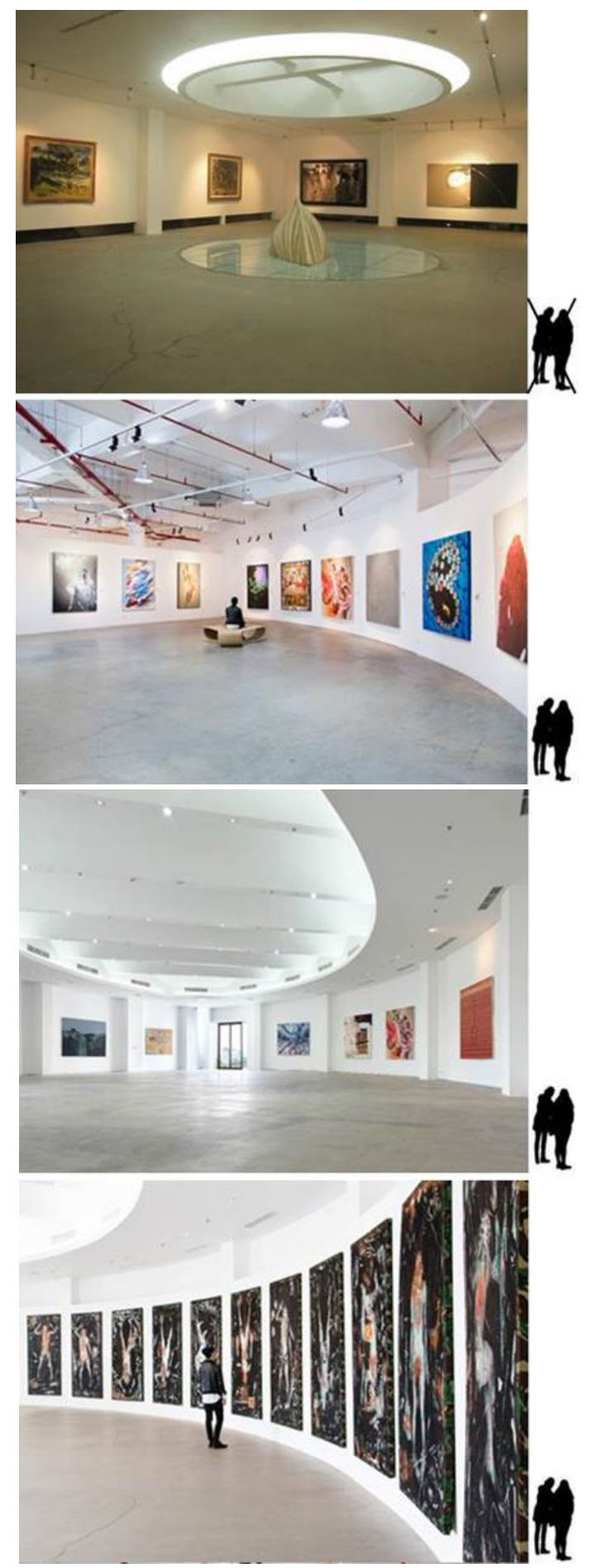

Gambar 2 Mondecor Art:1 di Jakarta. (sumber foto: http://www.mondecor.com/)
Pada Gambar 2. dapat terlihat bahwa diantara ruang-ruang pameran yang tidak bersudut, ada satu ruang pameran yang memiliki sudut, seperti yang tertera di Gambar 2. paling atas menjadikan rangkaian alur berubah menjadi terasa kaku sehingga pengalaman ruang yang tadinya mengalir menjadi terasa tidak mengalir kembali.

Selain itu, pencahayaan pada Gambar 2. paling atas berbeda dengan pencahayaan pada ruang-ruang lain, sehingga pengalaman yang didapat akan berubah karena kurangnya keharmonisasian pada pencahayaan.
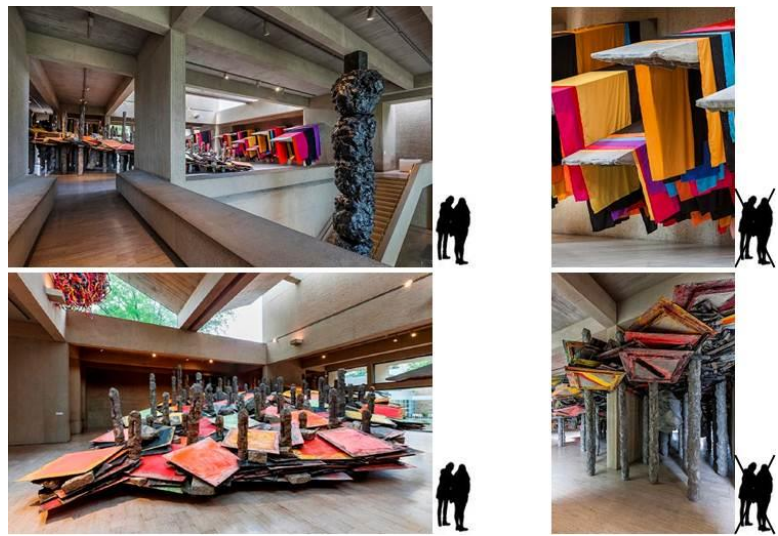

Gambar 3 Des Moines Art Center, di Iowa. (sumber foto: http://www.desmoinesartcenter.org/)

Sementara itu, pada Gambar 3. terlihat tipologi yang berbeda dari sebelumnya, karena rasa ruang yang berskala monumental, sehingga bersifat megah. Akan tetapi, apa yang terlihat pada bagian kanan atas dan kanan bawah, kemegahan tersebut hilang dan memberikan narasi yang berkesan sempit, meskipun skala yang diberikan merupakan skala monumental karena peletakan karya seni yang berhimpitan.

Disini dipahami bahwa kedua tipologi memiliki kualitas ruang yang berbeda. Hal-hal tersebut dapat dijadikan sebagai bahan pembelajaran karena masing-masing ruang pameran memiliki skala ukuran terhadap bentuk karya seni yang berbeda. Menurut Francis D.K. Ching (2012) arsitek merangkai elemen-elemen yang membentuk ruang dari adanya hubungan majemuk antara ruang dan unsur-unsur lain yang mendukung, kemudian diolah sebagai pemenuhan kebutuhan ruang yang mampu membangkitkan emosi. Disini, pemahaman emosi merupakan peranan psikologi arsitektur dimana emosi seseorang dapat meningkat atau menurun ketika ia berada di dalam suatu ruangan dengan berbagai pengaruh atau kondisi. 
Sehingga, sudah tentu jika ruang-ruang yang dibutuhkan untuk satu macam karya seni dan karya seni lain yang memiliki skala berbeda, pasti memiliki kebutuhan ruang yang berbeda. Namun, bukan berarti ruang yang akan diciptakan harus menyesuaikan bentuk karya seni, melainkan lebih kepada bagaimana narasi rangkaian alur dan pengalam ruang yang didapat oleh pengunjung saat menikmati karya seni yang beragam.

Pemahaman yang didapat dari tipologi kemudian dihubungkan dengan rangkaian alur dan pengalaman manusia. Bukan hanya berasal dari memahami pengalaman rasa ruang yang didapatkan dari indera penglihatan saja, tapi juga berasal dari pengalaman terhadap dua (2) hal yaitu: alur (narasi) dan perjalanan (tour). Dimana menurut pemahaman dijelaskan bahwa alur (narasi) yang terbentuk dalam dimensi ruang dan waktu dimana proses melihatnya berdasarkan perjalanan (tour) yang dilakukan dalam mengelilingi galeri seni.

Selama melakukan perjalanan, tentu skala dan proporsi ruang akan mempengaruhi pengalaman yang dirasakan oleh pengunjung, bukan hanya sekedar hubungan antara lantai, dinding, dan langit-langitnya, tetapi harus dipikirkan juga bagaimana sirkulasi, serta lebar dan panjang ruang, dan ketinggian langit-langit yang kiranya sesuai. Pengolahan elemen-elemen tersebut sebagai pemenuhan kebutuhan ruang yang mampu memberikan pengalaman tertentu bagi pengguna. Serta, memaksimalkan manfaat dari fungsi ruang yang dicapai dengan fokus pada bentuk, ruang, dan tatanan secara arsitektur agar ruang memberi kesan psikologis yang positif.

\section{PENUTUP}

\section{Simpulan}

Desain ruang akan mempengaruhi manusia (pengunjung) ketika mereka bergerak melalui ruang (galeri seni). Adanya pergerakan dan observasi manusia dalam ruang, dapat menciptakan keselarasan antara rangkaian alur dalam ruang-ruang pameran di galeri seni.

Ketika pengunjung memasuki ruangruang yang ada pada galeri seni, secara sadar ataupun tidak sadar, mereka memberi respon terhadap unsur-unsur yang ada pada ruang, yang mana hal tersebut memberikan pengalaman yang berbeda bagi setiap individu, namun tetap memiliki satu inti, yaitu keselarasan.

Dari hal-hal diatas, saya mengangkat sirkulasi yang berlanjut atau sirkulasi kontinuitas (continuity circulation) sebagai temuan untuk ide utama penerapan keselarasan rangkaian alur (narasi) dan pengalaman ruang dalam psikologi arsitektur.

Sirkulasi kontinuitas diciptakan dimana pengunjung berjalan melalui area ruang pamer pada galeri seni yang mengalir, ada space untuk berbelok secara halus (tidak tiba-tiba) atau berjalan terus tanpa harus memutar arah, dan tidak menemui jalan buntu (dead end) sehingga para pengunjung dapat terus menikmati observasi dari pameran karya seni yang dipajang secara terus menerus, dimulai dari ketika mereka pertama kali mengawali perjalanan hingga mengakhiri perjalanan dengan santai.

\section{Saran}

Penelitian ini merupakan penelitian terhadap perancangan dan perencanaan dalam desain arsitektur terkait fungsi dan/atau jenis bangunan galeri seni, namun kedepannya penelitian ini dapat dikembangkan untuk fungsi dan/atau jenis bangunan diluar galeri seni. Karena keselarasan antara rangkaian alur sirkulasi kontinuitas dengan pengalaman narasi arsitektur yang didapatkan dari observasi dan perjalanan itulah yang membuat orang merasa terhubung dengan ruang yang telah dilalui.

\section{DAFTAR PUSTAKA}

\section{Buku}

Creswell, J. 2002. Educational research: Planning, conducting, and evaluating quantitative and qualitative research. Upper Saddle River, NJ: Merrill Prentice Hall.

de Certeau, Michel. 1984. The Practice of Everyday Life. English Translation by Stefen F. Rendall. University of California Press. Berkeley and Los Angeles, California.

Ching, Francis D. K., Binggeli, C. 2012. Interior Design Illustrated. 3rd ed. Canada: John Wiley and Sons, Inc.

Halim, Deddy. 2005. Psikologi Arsitektur Pengantar Kajian Lintas Disiplin. Jakarta : Grasindo

Oxford Dictionaries. Oxford Dictionary of English. Published by the Oxford University Press Oxford University Press.

Patridge, Eric. 1977. Origins: A Short Etymological Dictionary of Modern English. MacMillan Publishing Company, Inc. (NY).

Raffestin, C. 1980. Pour une géographie $d u$ pouvoir. Paris. 
Jurnal

Colquhoun, Alan. 1996. Typology and Design Methods. Kate Nesbitt (Ed), Theorizing A New Agenda for Architecture: An Anthology of Architectural Theory 19651995. Princeton Architectural Press, 1996.

Patchett, J. M., G. Wilhelm. 1995. Designing sustainable systems: Second International Green Building Conference and Exposition. A. H. Fanney, K. M. Whitter, and T. B. Cohn, eds. NIST Special Publication 888.

Schmidt, Kjeld., Wagner, Ina. 2001. Ordering System in Architectural Design and Planning. Position paper for Workshop on Infrastructures for Distributed Collective Practice, San Diego, 6-9 February 2001.

Yatmo, Yandi Andri., Atmodiwirjo, Paramita., Paramita, Kristanti Dewi. 2013. Whose waste is it anyway? Journal of Urban Design, 18:4, 534-552. 